Macedonian Pharmaceutical Bulletin, 66 (Suppl 1) 41 - 42 (2020)

Online ISSN 1857 - 8969

UDC: $616-001.17-083.2$

DOI: $10.33320 /$ maced.pharm.bull.2020.66.03.020

Short communication

\title{
Nutritional support in a patient with burns
}

\author{
Suzana Atanasovikj*, Bojana Janeku, Dafina Boshkoska, Menka Andreska, \\ Elena Karabeleski, Dragana Mladenovska, Kristina Mladenovska, Lidija Petrushevska- \\ Tozi, Aleksandra Kapedanovska Nestorovska, Tanja Petreska Ivanovska
}

\section{Faculty of Pharmacy, Ss. Cyril and Methodius University, Mother Theresa No. 47, 1000 Skopje, N. Macedonia}

\section{Introduction}

Metabolism of patients with burns is increased, sometimes even doubled and it takes time to return to normal. Severe catabolism leads to body mass reduction and decrease in immune system function. Increased oxygen consumption throughout the body increases ATP levels and thermogenesis. Reactions that consume ATP are mostly from the hyperbolic response to burns (57\%), including ATP for protein synthesis, the production of ATP required for hepatic gluconeogenesis and the glucose and fatty acid cycle (Williams et al., 2009).

Inhibition of the catabolic hormones epinephrine, cortisol and glucagon leads to inhibition of the protein synthesis and lipogenesis. Protein decomposition becomes a necessary and major source of energy, hence skeletal muscle cohesion results with a long-lasting imbalance between protein synthesis and degradation (Clark et al., 2017).

Adequate fast nutritional intervention is very important in preventing complications. Early enteral nutrition reduces circulating catecholamines which preserves intestinal mucosal integrity, motility and circulation, improves muscle mass maintenance and heals wounds (Rodriguez et al., 2011).

This study aimed to illustrate the scale of dietetic activities and to identify nutritional interventions since nutritional support is a critical aspect of the treatment of burn patients.

\section{Case presentation}

A 33-years old patient $(76 \mathrm{~kg}, 180 \mathrm{~cm})$ jumped through the window escaping from fire. First aid examination found burns on the extremities, scalp, face, chests and on the back (90\% of the body surface). There was a suspicion that the fibulae on the left leg was fractured and that there was an injury of the left wrist joint.

Upon admission in the hospital, oxygen was administered through a mask. Due to suspicion of inhalation burns, he was intubated with $7.5 \mathrm{~mm}$ endotracheal tube. Analgesics and intravenous fluids were given and mechanical ventilation was provided. Patient was transferred to Intensive care unit after the fracture surgery was completed.

On the third day of hospitalization, the patient had burns covering $60 \%$ of the skin. The body temperature was $38{ }^{\circ} \mathrm{C}$. Laboratory results were: increased bilirubin concentration and transaminases (ALT $900 \mathrm{U} / \mathrm{L}$, AST $700 \mathrm{U} / \mathrm{L}$ ), increased alkaline phosphatase (680 U/L) and albumin (> 35g/dL), increased prothrombin time, urea $13.2 \mathrm{mmol} / \mathrm{L}$, sodium $116 \mathrm{mmol} / \mathrm{L}$, potassium $6.5 \mathrm{mmol} / \mathrm{L}$. The patient also had another diagnosis, epilepsy treated with oral valproic acid with controlled release.

*atanasovicsuzana@yahoo.com 


\section{Discussion}

The patient had normal value for BMI (23.5). The primary nutritive support for this patient is to meet the increased caloric requirements caused by the hypermetabolic state and to avoid over-eating. Energy needs are changed and fixed formulas usually lead to insufficient food intake for the time of the maximal energy utilization as well as to overfeeding during the later period.

Indirect calorimetry (IC) is a golden standard for measuring the energy consumption, by recording the volume of inhaled and exhaled concentrations of oxygen and carbon dioxide through face mask or by pressurized air cooler. The ratio of produced $\mathrm{CO}_{2} v s$. consumed $\mathrm{O}_{2}\left(\mathrm{VCO}_{2} / \mathrm{VO}_{2}\right)$ which is influenced by the metabolism of specific nutrients, gives the respiratory quotient (RQ) used to detect overfeeding or underfeeding. Normal metabolism of mixed nutrients yields a RQ of about 0.75-0.90 (Stödter et al., 2018).

Carbohydrates compared to fats are more suitable source of energy at patients with burns, but the glucose oxidation is limited and its need at burned patients is normally increased. Having in mind the possibility that insulin resistance could happen in this kind of injury, patients could benefit from additional insulin therapy. Insulin therapy promotes muscle protein synthesis, wound healing, improves donor healing places, bone mineral density and can reduce spent in the intensive care unit. The optimal maintenance glycemia is $8 \mathrm{mmol} / \mathrm{L}$. In addition, carbohydrates promote wound healing and have a protein like effect. Fats are nutrients needed to prevent deficiency in essential fatty acids but are recommended only in limited quantities. In burns, lipolysis is suppressed and the use of lipids for energy production is also reduced. Increased betaoxidation of fats provides fuel during the hypermetabolic state, but only 30\% of free fatty acids are degraded and re-esterified and later accumulated in the liver. Increased intake of fats may have adverse effects on the immune system and therefore diets with reduced fats intake are generally recommended (fats composition is highly important). The optimal intake is $2 \mathrm{~g}$ fats $/ \mathrm{kg}$.
Regarding the use of proteins, it is important to mention that proteolysis is significantly increased in severe burns and a patient could lose half a kilogram of skeletal muscle per day. Proteins are a major source of energy but addition of extra calories would not increase protein synthesis, it will lead to overeating. The calorie-protein ratio should be 150:1 in severe burns. Severe burns lead to intense oxidative stress which combined with inflammatory response leads to depletion of endogenous antioxidant deficiency that is highly dependent on micronutrients (vitamin $\mathrm{A}, \mathrm{E}, \mathrm{C}, \mathrm{D}_{3}, \mathrm{Fe}, \mathrm{Cu}, \mathrm{Zn}, \mathrm{Se}$ ).

\section{Conclusion}

For the patient with severe burns, enteral nutrition with specific types of nutrients and a customized formula according to the patient's nutritional needs is recommended. Monitoring should include daily weight control and energy intake needs, nitrogen balance, electrolyte balance, fluid-preventing malnutrition needs and muscle mass recovery.

\section{References}

Clark, A., Imran, J., Madni, T., Wolf, S.E., 2017. Nutrition and metabolism in burn patients. Burn Trauma 5. Available at: https://doi.org/10.1186/s41038-017-0076-x/s41038017-0076-X.

Rodriguez, N.A., Jeschke, M.G., Williams F.N., Kamolzet, L-P., Herndon, D.N., 2011. Nutrition in burns: Galveston contributions. JPEN J. Parenter. Enteral. Nutr. 35, 704-714.

Stödter, M., Borrelli, M.R., Maan, Z.N., Rein, S., Chelliah, M.P., Sheckter, C.C., Duscher, D., Tapking, C., Branski, L.K., Wallner, C., Behr, B., Lehnhardt, M., Siemers, F., Houschyar, K.S., 2018. The role of metabolism and nutrition therapy in burn patients. $\mathrm{J}$. Nutr. Food Sci. 8(6). Available at: https://doi.org/10.4172/2155-9600.1000741.

Williams, F.N., Herndon, D.N., Jeschke, M.G., 2009. The hypermetabolic response to burn injury and interventions to modify this response. Clin. Plast. Surg. 36, 583-596. 